\title{
Introduction. Subjectivity and Emotion in the Individual and the Group
}

\author{
Peter Hertel-Storm \\ Education at Boulevarden, UCL University College, Vejle, Denmark \\ Department of Design and Communication, University of Southern \\ Denmark, Kolding, Denmark \\ plst@ucl.dk
}

\section{The Conference}

On February 28, 2019, the doors opened for the 2oth Anniversary Annual Meeting of the Danish Philosophical Society. As is customary, this meeting was a national conference with invited keynote speakers and other international guests and participants. This meeting was noteworthy for at least two reasons other than the anniversary itself. First, it was held in the relatively academically insignificant Danish city of Vejle. Second, it was hosted by an innovation and entrepreneurship education department at a university college of applied science, and not, according to custom, by a philosophy department at a major Danish university.

The three keynote speakers, Dan Zahavi from the University of Copenhagen, Achim Stephan from the University of Osnabrück, and Helena De Preester from Ghent University, have all contributed to this volume. In fact, it was during the conference itself that Asger Sørensen, the chairman of the Danish Philosophical Society, and I decided to propose devoting an issue of the Danish Yearbook of Philosophy to the same theme explored in the conference: "Subjectivity in the Individual and the Group." "Emotion" was added later, as we were preparing the call for papers, because I wanted to indicate a focus that had clearly been emerging at the conference itself. The question of subjectivity, intersubjectivity, and sociality was largely discussed with reference to emotionality in general, and social or shared emotions in particular.

When I wrote these pages, I was eager to include a list of people who should be mentioned, people toward whom I feel gratitude for helping to make the 
conference work. But soon the list became too long for this introduction, as it included colleagues, students, members of the Danish Philosophical Society, friends, professors, researchers, and others who all freely offered their time and effort in order to realize the event.

Although I would like to think that it was because of my leadership and skills as an event manager that everything came to pass in the way it did, the truth is rather that we were a group of people who had a pioneer feeling as well as a joint interest in making something memorable together. This was a vision, or perhaps a feeling of engagement that was shared among everyone present, even though they did not all know each other, and furthermore I suspect they had a very different idea of what the result of their efforts was going to be.

A few days after we finished the conference, I came back to check if the auditorium, rooms, and so on had been properly cleaned up and restored to the state in which we found them. While removing the last posters and listening to the silent echoes of my memory's many voices from the conference, it came to me as an epiphany that the practical and entrepreneurial aspects of arranging of the conference were perhaps exactly the same as its philosophical theme: a group belief, a common vision, a shared emotion.

This thought would not let me go: Could it be true that, in some philosophically significant sense, an emotion had been shared by the group? How could I know that it was not just my fallible perception of the situation? Could this kind of emotion play a part in bridging individual subjectivity and intersubjectivity? Was my emotional state caused by the others' emotional state, or by the fact that we shared a physical or psychological context that, in some way or other, scaffolded my emotional state — as when music puts us all in the same or a similar mood, or we design our meeting rooms in a particular way? Or was it perhaps the case that our bodily expressions and sensations in some way communicate with each other on an emotional level?

These and related questions were taken up at the conference and are the center of attention of the contributions in this volume. Behind the discussions lie a complex philosophical debate on the nature of emotions and subjectivity that goes back to at least Descartes. Questions of how to make a transition from individual subjectivity to intersubjectivity, and of the constitution of emotions - particularly in relation to cognition, embodiment, and sociality-have a complicated academic history.

In this introduction I will sketch the Cartesian foundation, as well as a few central themes in the background philosophy of emotions, in the hope that this may facilitate some readers' engagement with the contributions. 


\section{With or without Common Sense? Escaping a Danish-Built Trap}

When Descartes argues in favor of mind-body dualism in his second and third meditations, he also unwillingly develops the mind-body problem. ${ }^{1}$ Adding a Danish perspective, this is what the late philosopher David Favrholdt once called "the Cartesian trap," in his controversial Filosofisk Codex (1999). ${ }^{2}$ The Cartesian trap captures the idea that once one buys in to the fundamental distinction between mind and body proposed by Descartes, there is no way back to the external world and solipsism follows. Because the starting point must always be the res cogitans itself, granted that it alone has the ability of thought and perception, and therefore of criticism and philosophical scrutiny, it can never access the res extensa, which is defined as something qualitatively different than itself.

We might think of the mind as consciousness or as thoughts emerging from or supervening on biological complexity in the brain or central nervous system. Or we might think that the physical world is just inferred from impressions on the sensory system, or perhaps that it is no more than a phenomenological quality of embodiment. If we do so we are indeed still caught in the Cartesian trap. When we engage in discussions with such premises, we become reductive materialists who cannot explain subjectivity, or idealists for whom the physical world can be nothing but experienced phenomena.

The game-changing question is the question of what exactly we refer to when we talk about the mind or res cogitans. If we see it as a class or a container, what, then, might be in it? We might distinguish between rationality, emotionality, beliefs, thoughts, representations, attitudes, perceptions, phenomena, and many other elements. Furthermore, we might disagree about the classifications and distinctions, both in terms of what is a category of what, and what is an element of what.

1 René Descartes, Meditationes de prima philosophia (1641), in Oeuvres de Descartes, vol. 7, ed. Charles Adam and Paul Tannery (Paris: Libraire Philosophique, 1983); translated by Donald A. Cress in "Discourse on Method" and "Meditations on First Philosophy," 3rd ed. (Indianapolis: Hackett, 1984).

2 David Favrholdt, Filosofisk Codex (Copenhagen: Gyldendal 1999), 19. In his later works Favrholdt adopted a lighthearted style, showing little respect for philosophical terminology and technicalities. I have therefore rephrased his definition of the Cartesian trap. Favrholdt's Danish text can be translated as follows: "As everything I can know (erkender) can only become knowledge by being experienced by me, that is by 'entering the consciousness,' I can in fact never know if anything exists 'outside' the consciousness." 
However, a question that has been more recently asked is: Are all contents of the individual mind necessarily individual? Could it be that we have some elements in our mind that are socially generated? Is there such a thing as a social emotion or belief induced exclusively by the group? Though many of us would, in our commonsense modes, readily accept this, the Cartesian trap shows us that it is not at all an easy task to understand this. This notion of social emotions or group-induced beliefs, however, is what is being proposed by some in this volume. This is in common sense straightforward, in philosophy somewhat controversial. As David Hume famously wrote in the Treatise on Human Nature:

Where am I, or what? From what causes do I derive my existence, and to what condition shall I return? Whose favour shall I court, and whose anger must I dread? What beings surround me? and on whom have I any influence, or who have any influence on me? I am confounded with all these questions, and begin to fancy myself in the most deplorable condition imaginable, inviron'd with the deepest darkness, and utterly depriv'd of the use of every member and faculty.

Most fortunately it happens, that since reason is incapable of dispelling these clouds, nature herself suffices to that purpose, and cures me of this philosophical melancholy and delirium, either by relaxing this bent of mind, or by some avocation, and lively impression of my senses, which obliterate all these chimeras. I dine, I play a game of backgammon, I converse, and am merry with my friends; and when after three or four hours' amusement, I would return to these speculations, they appear so cold, and strained, and ridiculous, that I cannot find in my heart to enter into them any farther. ${ }^{3}$

Though the social itself may be a commonsense fact, the effort to establish it philosophically is by no means easy and requires a revision of philosophical assumptions, in turn perhaps leading to a revision of our common sense as well.

Therefore, a simple way of getting out of this trap, and one that seems not to be available to us, is by simple postulation in terms of common sense. It might be tempting to argue, somewhat along the lines of Hume's thinking, that the very claim that the world or other people does not exist is stupid and a result of philosophers' tendency to overthink everything.

3 David Hume, A Treatise on Human Nature, 2nd ed. (Oxford: Oxford University Press, 1978), book 1, pt. 4, sec. 7, p. 269 . 
But this would be to confuse the answer with the question. The answer is not to adapt our commonsense reality as an automatic defensive response: I am here, you are there, the world is out there. Instead, we need to search for a way to philosophically justify this view. As Descartes prominently pointed out in his skeptical approach in the first meditation, and as many others have done since, the distinction between the I, the We, and the World is not self-evident.

However, it is also possible to produce a 'common sense strikes back' argument, a retort to the kind of argumentation outlined above. This criticism of simple or informed common sense proposes that a group or society imposes beliefs on the individual, perhaps for selfish or political reasons, and presses individual philosophers to conform to some views, beliefs, or standards of the group. But if this is the case, it already involves a group belief, as something other than an individual belief, which is exactly what we originally had a problem constituting.

Perhaps one could argue that this is the real nature of the Cartesian trap: that you need to begin with asserting the group, because one cannot conclude more than is already in the premises. Skeptics will reply that this is an ad hoc argument, a fallacy of the same kind we discover in Descartes's Meditations and later in Leibniz's Monadologie, ${ }^{4}$ when they appeal to God in order to make this exact transition from the individual to the group.

However, there is a further twist related to importing this commonsense argumentation, which might soften things up. When appealing to common sense, as we did above, we are presupposing that the concepts are simple and well-formulated. Nevertheless, on closer scrutiny, it is not always clear what the assumption of a group would actually amount to, as the following line of thought indicates.

Does everyone in a group have the same account of who the group members are, how the group is structured, or whether the group organization resembles a set, a class, a bare plurality, a mechanism, or an organism? In addition, the question of whether 'elements,' 'members,' or 'parts' in this context are three words for the same thing, or whether they perhaps indicate a significant difference, may or may not be essential. Therefore, it is not always clear exactly what the assumption of a group would amount to, not only in terms of an epistemological or ontological commitment, but also logically, in terms of what can be inferred from that assumption.

4 These particular arguments are found in Descartes's third and fifth meditations and in Leibniz's Monadologie, in Gottfried Wilhelm Leibniz, Die philosophischen Schriften, vol. 6, ed. C. I. Gerhardt (Hildesheim: Olms, 1965). 
When we, as a starting point, consider the very assumption of the group in an individual subject, then we must face the fact that common sense will play a role, but that it is perhaps not common and that it is perhaps not a well-formed formula, but just a well and strictly understood belief. Perhaps this belief is really founded in a different way?

The question therefore naturally turns toward the question of whether there are other ways to make the transition from the individual to the group, rather than a rational enlightened commonsense approach. Some recent answers to this question, including those in this issue, are twofold:

First, if we consider immediate phenomenal experience as a supplement to pure reason, we might hope to find a more specific or clearer idea there, and perhaps even a warrant for the transition from the individual to the group.

Second, the emotions seem to be overlooked in what is considered above, and there might be properties of emotionality in general that would clarify or warrant the transition; or we might discover special kinds of emotions, for example 'social emotions' or 'shared emotions,' that might do the job.

The first step is therefore not to justify an assumption of the group, but to understand how the psychology of the group would work. At this point the emotions are currently taken to play a significant role, because we might be able to understand our common understanding of the social by focusing on the transmission and sharing of emotionality. This is the feeling of many philosophers: that as long as we stay with the emotions, we can avoid being caught in the Cartesian trap, even though we can always see it as a dark cloud looming on the horizon.

\section{What Is an Emotion?}

Descartes himself was alert to the possibility that the emotions play a role in performing this transition from the individual to the group. In his last work, The Passions of the Soul, ${ }^{5}$ he pointed out the ontological significance of the embodiment of the emotions. He attempted to couple this with the thesis on the pineal gland as the mediator between mind and body. Many philosophers thereafter began to consider the role of the emotions, from Spinoza to Hume to Darwin, leading to Le Bon's theory of affective transmission in crowds, and

5 Rene Descartes, Les passions de l'âme (1649), in Oeuvres de Descartes, vol. 11, ed. Charles Adam and Paul Tannery (Paris: Libraire Philosophique, 1983); translated by Michael Moriarty as The Passions of the Soul (Oxford: Oxford University Press, 2015). 
most importantly the feeling theory of William James and Carl Lange, particularly James's paper entitled "What Is an Emotion?" (1884) as well as the milestone work The Principles of Psychology (1890). ${ }^{6}$ Here James argues that emotions are inner perceptions of physiological changes, caused by sensations and impressions. Hence emotions are essentially perceptions and are regarded as a somewhat passive response to external stimuli. Further, they are embodied in the sense that they are seen as inner feelings, essentially connected to a particular sensory input. ${ }^{7}$

An alternative view to the feeling theory is the cognitivist view that partly developed in opposition to James and Lange. Instead of working with sensory input as the cause of emotions, cognitivists typically work with beliefs. To paraphrase Robert Solomon, I may believe that John stole my car, and develop the appropriate attitude and evaluate John accordingly, whether or not he actually did. ${ }^{8}$

This idea of attitudes comes, at least in part, from Jean-Paul Sartre's notion that emotions can be seen as replacements for inappropriate actions. The idea is that if I am inclined to hit John in the face for stealing my car but I refrain because it is an inappropriate action, then I replace my course of action with an emotion - an angry attitude toward John. The function of the cognitive component was later developed and stressed in the famous Schacter-Singer experiment. ${ }^{9}$ On the basis of this experiment, it was argued that the emotional

6 For Spinoza's account of emotions, see Ethica III in Spinoza: Opera Posthuma, ed. Carl Gebhardt, 4 vols. (Heidelberg: Winter, 1924). Discussions of his contemporary relevance can be found in Desire and Affect: Spinoza as a Psychologist, ed. Yirmiyahu Yovel (New York: Little Room, 1999). David Hume's discussion of emotions is found in the Treatise on Human Nature, where the entire second part is devoted to the passions. Charles Darwin's account is found in his The Expression of the Emotions in Man and Animals (1872), anniversary ed. (London: Harper Perennial, 2009). For Gustave Le Bon's account of affective transmission, sometimes referred to as "contagion theory," which was perhaps first formulated in his work La psychologie des foules (1895), see Gustave Le Bon, The Crowd: A Study of the Popular Mind (New York: Dover, 2002): 10-24, 38-42, 77-89. References to the James-Lange theory implicitly point to the following publications: William James, "What Is an Emotion?," Mind 9, no. 34 (1884): 188-205; William James, "The Emotions," in The Principles of Psychology, vol. 2, authorized ed. (New York: Dover, 1950), 442-485; Carl Georg Lange, Om sindsbevcegelser: Et psyko-fysiologisk studie (Copenhagen: Jacob Lund, 1885).

7 For a recent defense of a neo-Jamesian approach, see Jesse Prinz, Gut Reactions (Oxford: Oxford University Press, 2004).

8 Robert C. Solomon, "Emotion and Choice," in What is an Emotion?, ed. Cheshire Calhoun and Robert C. Solomon (Oxford: Oxford University Press, 1984), 305-326.

9 Jean-Paul Sartre, Esquisse d'une théorie des émotions (Paris: Editions Hermann, 1939), translated by Bernard Frechtman as The Emotions: Outline of a Theory (New York: 
response to a particular impulse - in the experiment, a questionnaire containing some highly provocative assumptions - depends in part on the actor's interpretation and experience of the context, particularly other subject's emotional responses to the same and similar events. So if I sit in a room with other people and fill out the questionnaire containing provocative questions, my emotional response will depend on my perception of how the other people in the room are reacting.

Schacter ${ }^{10}$ seems to attempt to incorporate both cognitive and embodiment aspects, which should probably be seen as an attempt to integrate the JamesLange feeling theory with the competing Cannon-Bard appraisal theory. ${ }^{11}$ The latter had increased in popularity at the time and grew out of experimental results that seemed to question the James-Lange theory. Together, Schacter's and Sartre's views formed the inspiration for what was later called the cognitive theory of emotion, or sometimes the propositional attitude theory.

The cognitive theories were a group of views that therefore appeared in many forms and shapes. Robert Solomon argued that emotions are intimately coupled to value creation, as a person's attitude toward an object, ${ }^{12}$ based on a belief, creates this object as a value to the person holding the attitude. Ronald de Sousa ${ }^{13}$ pointed out that emotions perhaps had a more passive role, in the sense that they are perceptions, but perceptions of value (what he called the "axiological level of reality") created by a means-end rationality: an object has value insofar as we think of it as a good or bad means to obtain a certain end. In cognitive psychology in the early 1980s, there was a heated debate between Richard Lazarus and Robert Zajonc on the nature of cognition in emotions. ${ }^{14}$ The debate was over whether emotions required high-level information processing of sensory input or whether in some cases there can be more direct neural pathways.

Philosophical Library, 1948); Stanley Schachter and Jerome Singer, "Cognitive, Social, and Physiological Determinants of Emotional State," Psychological Review 69, no. 5 (1962): 379-399.

10 See Stanley Schachter, Emotion, Obesity, and Crime (New York: Academic, 1971).

11 Walther B. Cannon, Bodily Changes in Pain, Hunger, Fear, and Rage, 2nd ed. (New York: Appleton, 1929).

12 Robert Solomon, The Passions (New York: Anchor Doubleday, 1977).

13 Ronald de Sousa, The Rationality of Emotion (Cambridge, MA: MIT Press, 1987). De Sousa writes explicitly, "Emotions are a kind of perception-perception of the axiological level of reality. And the reality they reveal is one that is tragically rich with an irreconcilable plurality of value" (332).

14 See particularly Robert Zajonc, "Feeling and Thinking: Preferences Need No Inferences," American Psychologist 35 (1980): 151-175; Richard Lazarus, "Thoughts on the Relations between Emotion and Cognition," American Psychologist 37 (1982): 1019-1024. 
Following this line of thought, Robert Gordon suggested a distinction between how emotions are founded and how they are grounded, ${ }^{15}$ a distinction that in principle can be applied to both cognitive and feeling theories of emotion. This opens up the discussion to classical developmental psychology and the theories formulated by Jung, Freud, and Piaget. The concept of grounding leads us to think about individual psychological backgrounds and their importance and influence in the unfolding of emotions in individuals, including individual stages of development or a proposed unconscious psychological constitution.

\section{Two Naturalistic Theories}

In the understanding of emotions that laid the groundwork for the discussion of emotions as outlined above, the emotions are locked on the individual: emotion may involve a belief in something that is supposed to cause it. It may be considered to be founded on the physiological effects of external causes, but it is grounded in the constitution of the individual.

However, we might prefer an understanding that involves both cognitive, behavioral, appraisal, and physiological arousal elements, which gives us more options to find an understanding of some of these elements, or perhaps a configuration of understandings, that can aid us in bridging between the individual and the group.

Accepting the 'we cannot go with commonsense solutions' argument above, we cannot simply claim our way out. But still, the example of arranging a conference as a joint experience or perhaps a shared emotion, together with experiments like the one Schachter and Singer conducted, seem to suggest that we should conduct investigations into the social psychology of groups.

On this ground, however, we find naturalists and constructivists in conflict. Paul Ekman has famously argued for a highly naturalistic affect program theory, ${ }^{16}$ which, as I see it, attempts to make use of a specific configuration of elements from the feeling and cognitive theories in order to elucidate some natural biological pattern of emotions that can be explained in a social developmental psychology setting. Ekman draws attention to facial expressions and how different configurations of muscle tension are at stake when we react emotionally. As such, he is receptive to the Schacter-Singer point of social context

\footnotetext{
15 Robert Gordon, The Structure of Emotions (Cambridge: Cambridge University Press, 1987).

16 Paul Ekman, Emotions in the Human Face (New York: Pergamon, 1972); Paul Ekman, The Face of Man (New York: Garland, 1980).
} 
perception, as well as pointing toward appraisals, attitudes, and bodily arousal, but at the same time he follows the lead of Darwin. Furthermore, these configurations also give rise to a higher-level discourse on basic emotions, constituted by these modules or affect programs, as he labels them. So based on this theory, we can investigate emotions as a component of group instigations, and because group members can recognize particular affect programs in different situations and groups, we might extend our discussion to include the development of empathy, which Ekman divides into three categories: cognitive, emotional, and, in his later works, compassionate. ${ }^{17}$

Another naturalist, Antonio Damasio, has developed a feeling theory that can be compared to the James-Lange theory, but Damasio has a more exclusively biological approach that favors biological reductionism. He famously pointed out that emotionality plays an essential part in seemingly rational decision-making, at a time when cognitivists like Solomon and de Sousa pointed to an essential rationality of emotions. ${ }^{18}$ In later works, Damasio argues that homeostasis could be the central regulating dynamic on various levels: microbiological and personal as well as social. ${ }^{19}$ This idea of homeostasis in social constructions is not new, but Damasio's idea that affective constructions follow the same patterns on different biological levels, and therefore that our understanding of emotions can be, to some extent, recognized in higher-level biological orders like groups and societies, should raise some eyebrows.

Damasio, as I understand him, is arguing that when we consider cultures, there may not be any fundamental difference between the behavior of a bacterial culture compared to that of the culture of an organization or society. Our emotional behavior in groups, in the way psychologists like Ekman understand it, can be explained, according to Damasio, by biological mechanisms, and therefore we can give sense to them by importing a means-end rationality of the development of the whole.

Many have therefore doubted that emotions are a particular kind of natural object. For example, Rom Harrè has argued against basic emotions, particularly targeting naturalistic accounts like Ekman's, in order to support a constructivist view. According to Harrè there are individual differences between practically all cultures that seem to go against the naturalistic biological explanation model.

17 Paul Ekman and Wallace Friesen, Unmasking the Face (Englewood Cliffs, NJ: Prentice Hall, 1975); Paul Ekman, Emotions Revealed (New York: Henry Holt, 2003).

18 Antonio Damasio, Descartes' Error (New York: Putnam, 1995).

19 Antonio Damasio, The Strange Order of Things (New York: Pantheon Books, 2018). 
The debate is, as is common in discussions of constructivism and relativism, quite polarized. This has sometimes made it difficult to point to the similarities between Harré's and Ekman's approaches or to adopt insights from both views in a hybrid account. However, as interdisciplinarity in the field grew popular, attempts to bridge this vast variety of views and insights multiplied.

This diversification also gradually led to a differentiation of concepts of emotion. We have already come across the distinction between (cognitive) emotions on the one hand, and feelings on the other. Furthermore, we might distinguish between (cognitive) emotions that are value perceptions, as with de Sousa, and those that are attitudes, as with Robert Solomon. Similarly, we may distinguish between arousal (Schachter) and perception (James-Lange) theories of feelings. Some would import the distinction and some would not.

It is, however, exactly the tendency to rethink these matters in a new way that is currently underway, among both phenomenologists and naturalists. It can be seen as a reaching out toward both the insights of naturalists as well as constructivist social psychology. And it is from this movement that the contributions in this volume emerge.

\section{Subjectivity and Emotion in the Individual and the Group}

Dan Zahavi's contribution, "Du, Ich und Wir" (You, Me and We), was originally published in English in 2015 in the Journal of Consciousness Studies and is here presented for the first time in a German translation by Markus Seethaler. As part of Zahavi's exploration of 'we-ness,' it proposes to aid phenomenology in escaping the Cartesian trap and is based on a groundwork articulated in his book Self and Other (2014). ${ }^{20}$ Rehearsing the book's main argument in a 2015 publication, he writes:

I don't think a focus on phenomenal consciousness and an appreciation of the fact that we are first-personally acquainted with our own experiential life must go hand in hand with the view that the experiences of others are not manifest or present or given in any straightforward sense to us, and that second- and third-person ascriptions of mental states are consequently highly indirect, highly inferential endeavors. ${ }^{21}$

20 Dan Zahavi, Self and Other: Exploring Subjectivity, Empathy, and Shame (Oxford: Oxford University Press, 2014).

21 Dan Zahavi, "Self and Other: From Pure Ego to Co-Constituted We," Contemporary Philosophical Review 48 (2015): 149. 
In "Du, Ich und Wir," Zahavi follows the lead of Husserl and Scheler and argues against John Searle's theories of collective intentionality and standard conceptions of empathy. The feeling of 'we' is not sufficiently understood by positing joint intentional objects or empathic identification with an emotional state of 'another.' Hence 'we' must be seen as an emotional state that is intrinsically coupled to a particular phenomenal quality of 'we-ness.' Both Self and Other, as well as Zahavi's more recent paper "We in Me or Me in We? Collective Intentionality and Selfhood" (2021), can be seen as complementary works, each developing themes that are raised in the other. ${ }^{22}$

Zahavi models an approach based on introducing Edmund Husserl's phenomenology as a branch in cognitive science, which is otherwise mainly naturalistic. He argues for a collective intentionality that is present in some kinds of emotions and suggests that they might warrant emotional access to each other through empathy (miteinanderfühlen), but only in as much as we have a case of emotional sharing, a 'we' that has distinct phenomenological qualities.

Another approach is found in the contribution of Sabrina Coninx and Achim Stephan, "A Taxonomy of Environmentally Scaffolded Affectivity." Stephan is famous for his research on emergence in cognitive and biological systems as well as for his research on the emotions. ${ }^{23}$ Coninx has researched the psychology and phenomenology of pain. Together they argue, as I interpret them, that affective theories and concepts are so diverse that much can be gained by replacing them with a more unambiguous frame of reference. Focusing on situated cognition, "A Taxonomy of Environmentally Scaffolded Affectivity" maintains that the distinction between embeddedness and extendedness of affectivity should be replaced by a concept of affective scaffolding. This has at least two advantages, Coninx and Stephan argue. First, it avoids what seems to be a vague distinction, as well as all the futile discussions that may go along with that. Second, the focus on how external factors facilitate affectivity, including sentiments, feelings and emotions, involves a perspective that may be directly applicable to therapeutic practice and research.

The paper also more than hints at the fact that emotional states are to be regarded as affects and that they are affected by the surroundings and situational context. To go somewhat beyond the paper itself, this could mean that one can, to a certain extent perhaps, use people's surroundings not only as a

22 Dan Zahavi, "We in Me or Me in We? Collective Intentionality and Selfhood," Journal of Social Ontology 7 , no. 1 (2021): 1-20.

23 For his work on affective scaffolding, see particularly Achim Stephan and Sven Walther, "Situated Affectivity," in The Routledge Handbook of Phenomenology of Emotion, ed. Thomas Szanto and Hilge Landweer (London: Routledge, 2020), 299-311. 
semiotic system for 'reading' their emotional states, but also to explain how environmental changes may affect the emotions.

Therapeutic practice is also one of the main ends of Helena De Preester's and John Dorsch's paper "Descartes on the Passions of the Soul and Internal Emotions: Two Challenges for Interoception Research in Emotions." De Preester and Dorsch are both engaged in phenomenological approaches to emotion; De Preester is also particularly interested in the relations between emotions and art and technology. Together they argue that Descartes' notion of 'intellectual emotions' in The Passions of the Soul is a substantial though somewhat overlooked concept that could play a role in interoception-based research on the emotions. It is particularly the issue raised by Descartes himself, in terms accounting for both the feeling aspects as well as the cognitive aspects of emotions in his mind-body dualism, that creates this notion of 'intellectual emotions,' and therefore discussions of this notion often have ontological implications beyond where many phenomenologists would be willing to go, but where many naturalistic theories of emotions are essentially framed. The point is that the intellectual emotions also involve something like a feeling aspect, but that they are not felt as a direct perception in the way understood by James and other interoception approaches.

Gerhard Thonhauser has in previous publications explored various aspects of shared emotions. In his contribution to this volume, "Shared Emotions and the Body," it is exactly the embodiment of feelings that allows them to be shared. The feeling body itself is regarded as a sentient being, somewhere between mind and body, that leads to the thought of something between a neutral monism, Spinoza's dual aspect theory of mind and body, and Heidegger's Dasein. ${ }^{24}$ But being both the subject and object of feeling, feeling bodies can feel each other. Hence, what may seem to be opposing views-interoceptive views of feelings and emotions on the one hand and the phenomenology of shared emotions on the other-can in Thonhauser's view serve to enhance one another. He argues that bodily feelings — or rather feeling bodies engaged in a mutual incorporation, and therefore shared emotions-are not mysterious; this is the rule, rather than the exception.

In her contribution "Bodies-in-Relation: Fine-Tuning Group-Directed Empathy," Sarah Pawlet-Jackson considers empathy based on a critical

24 Thonhauser has published extensively on shared emotions and Heidegger's contribution to the phenomenology of emotion. See Gerhard Thonhauser, "Martin Heidegger and Otto Friedrich Bollnow," in The Routledge Handbook of Phenomenology of Emotion, ed. Thomas Szanto and Hilge Landweer (London: Routledge, 2020), 104-113; Gerhard Thonhauser, "A Multifaceted Approach to Emotional Sharing," Journal of Consciousness Studies 27, nos. 9-10 (2020): 202-227. 
expansion of Alessandro Salice and Joona Taipale's theory of group empathy. ${ }^{25}$ She points out that a key factor that perhaps has received too little attention in the literature is our ability to understand and experience interactions between other people, and to use that experience as a part of our empathy-based behavior and understanding of the group interactions we perceive and partake in. As such, a reading of her paper can place her analysis between those of Zahavi and Thonhauser, while at the same time complementing and being complemented by both of them. Furthermore, she has in a previous paper considered possible Gestalt (Ehrenfels) structures in intersubjectivity, and this concern seems to surface in several places in the paper, raising the question of potentially underlying mereological issues of wholes and parts. ${ }^{26}$

However, such mereological issues seem to be more distant from a naturalistic ontology of either the mathematical mereology of Stanisław Leśniewski, David Lewis, or perhaps Achille Varzi, or a Husserl-based material constitution mereology of the kind we find with David Wiggins or Peter Simons. ${ }^{27}$ Instead, perhaps it is necessary to found a whole new mereo-phenomenology that would attempt to investigate the phenomenology of what it like to have a part, or perhaps what it is like to be a part. There seems to potentially be a lot of background material to use as starting points in many areas, but mereophenomenology also seems like a new field that may prove useful when it comes to the experiential aspects of cognition.

Liselotte Hedegaard approaches a critique of the whole idea of body and mind by attending to the underlying phenomenology of place. Here one might expect the mereological aspect to be further elaborated, but Hedegaard points us back to the phenomenological foundation developed by Husserl. A place should not just be regarded as a position in an assumed geometrical space

25 Alessandro Salice and Joona Taipale, "Group-Directed Empathy: A Phenomenological Account," Journal of Phenomenological Psychology 46 (2005): 163-184.

26 See Sarah Pawlett-Jackson, "Gestalt Structures in Multi-Person Intersubjectivity," Synthese 198 (2021): 2365-2382. For the work of Christian von Ehrenfels, see “Über 'Gestaltqualitäten," in Vierteljahrsschrift für wissenschaftliche Philosophie 14 (189o): 249-292, and compare with the translation and discussion in Foundations of Gestalt Theory, ed. Barry Smith (Munich: Philosophia, 1988).

27 See Stanislaw Leśniewski, Collected Works (Dordrecht: Kluwer, 1992); David Lewis, Parts of Classes (Oxford: Basil Blackwell, 1991); Aaron Cotnoir and Achille Varzi, Mereology (Oxford: Oxford University Press, 2021). The constitution tradition often takes as its point of departure Edmund Husserl's third and fourth logical investigations; see Edmund Husserl, Logische Untersuchungen (1900-1901), 2 vols. (Tübingen: Max Niemeyer, 1993); Peter Simons, Parts: A Study in Ontology (Oxford: Clarendon Press, 1987); David Wiggins, Sameness and Substance (Cambridge, MA: Harvard University Press, 1980). Wiggins claims to be more inspired by Leibniz's Monadologie, but as I read him, he is essentially arguing a Husserlian view. 
occupied by a corporeal substance, but as constituted by the situatedness of the Cartesian subject. This is referred to by Husserl in Ding und Raum as the interplay between the Ich-zentrum and the Körper. ${ }^{28}$ This attempt to rethink the central distinction of mind and body, which underlies this whole issue of $D Y P$, stands as a phenomenological perspectivation, ending the issue at a place where a rational phenomenological constitution might after all become essential. And we might be left with the consideration of whether pure reason and emotionality should be regarded as primitives, or whether they inform or constitute one another.

The relationship between these contributions is intricate and complicated. On the one hand, they support and elaborate on each other, and they can be seen as forming a joint effort toward a common goal. On the other hand, they can also be read as a debate. The requirements of shared emotions in Zahavi's paper perhaps is too strong for Thonhauser's feeling bodies to meet. And whereas Coninx and Stephan as well as De Preester and Dorsch are targeting a relatively unambiguous distinction between mind and body, it is arguably more vague with Zahavi and Thonhauser. Again, we could argue that Hedegaard seems to be pointing toward an essential phenomenological trait that we have to consider as fundamental, or, on the contrary, that this approach will simply be left behind as the new era of the social phenomenology of shared emotions advances.

In the end, this issue of DYP presents a state-of-the-art report on an ongoing effort to understand subjectivity and its many forms and contexts. The work that has led to the publication has been extensive, and I would like to thank the reviewers and editors for their enthusiasm, and the authors for their patience. In particular I am grateful to Asger Sørensen, Finn Collin, and the staff at Brill for setting this opportunity in motion and helping out when necessary.

When I walk back to the location where the anniversary conference was held in 2019, I still feel the whispers from the walls reminding me of the event that led to this publication, a publication that forms a participation in an important effort to understand a difficult topic. It is not about who is right. It is about the fact that we all learned something. I continue to hear a voice in my head, discussing whether participation and sharing is, or should be, a mereological conception. I shake my shoulders and ignore the voice while I silently exit the building. But, as always, I remember to keep the door open behind me.

28 Edmund Husserl, Ding und Raum (Hamburg: Felix Meiner, 1991). 